\title{
Psychological symptom and its influencing factors among Chinese elementary school students during early COVID-19 outbreak: A cross-section survey
}

\author{
Xiaoshan Li ( $\sim$ boat010519@126.com ) \\ Jiangxi Normal University https://orcid.org/0000-0002-4316-5660 \\ Pengyong Sun \\ Jiangxi Normal University \\ Mingjie Zhou \\ Institute of Psychology Chinese Academy of Sciences

\section{Youtian Shen} \\ Shaanxi Normal University School of Psychology \\ Li Li \\ Jiangxi Normal University

\section{Lingling Huang} \\ No.8 high school, Beihai experimental school of Beijing

\section{Taohua Huang} \\ Huizhou Foreign Language school
}

\section{Research article}

Keywords: elementary school students, depression, anxiety, COVID-19-related stressors, coping, online learning satisfaction

Posted Date: April 1st, 2021

DOI: https://doi.org/10.21203/rs.3.rs-323521/v1

License: (c) (i) This work is licensed under a Creative Commons Attribution 4.0 International License. Read Full License 


\section{Abstract \\ Background}

This study aimed to examine the psychological symptom and its influencing factors among Chinese elementary school students during early COVID-19 outbreak.

\section{Methods}

A cross-section survey was used to investigate individual psychological response and its influencing factors among Chinese elementary school students. And the data were analyzed by the statistical software of SPSS 16.0.

\section{Results}

The results showed that students who experience large number of COVID-19-related stressors tend to report more depression and anxiety symptoms. Both problem-based coping and online learning satisfaction were protectors in predicting students' symptoms of depression and anxiety, while emotion-based coping was a vulnerable factor. With regard to demographic variables, students with low family social status reported more symptoms of depression and anxiety than those with high family social status.

\section{Conclusions}

These findings present implications for psychological inventions and for education counselling services during the pandemics.

\section{Background}

COVID-19 was called by WHO as a public health emergency of international concern because of its rapidity of transmission and causing vary degrees of illness ${ }^{[1]}$. As of March 15, 2020, a total of 150, 000 laboratory confirmed cases and 5, 720 death has been documented in 141 countries or areas ${ }^{[2]}$. As the most infected place, China Mainland has 80,844 laboratory confirmed cases and 3,199 death ${ }^{[3]}$. To block the spread of the virus, Chinese government takes many strict measures, including strengthening traffic control in each city, no mass gathering, closing non-essential public places, and replace off-line teaching with online teaching, and so on.

In addition to seriously threaten individual's physical health, the pandemic may have negative impact on individual mental health (e.g., depression) ${ }^{[4]}$. Previous study showed that the abnormal psychological phenomenon is common during SARS crisis ${ }^{[5]}$. A recent study showed that nearly $40 \%$ of 7202 adolescents ranged from 14-18 years reported the symptoms of depression and anxiety during COVID-19 pandemic ${ }^{[6]}$. Elementary school students are a transitional and critical developmental period in humans that is characterized by their brain and body maturation ${ }^{[7]}$. Comparing with people in other age stages such as secondary school 
students, high school students, college students, or other adults, elementary school students have unique characteristics in cognition development, self-awareness, socialization and so on. For elementary school students, poor mental health can compromise their development and future potential. And research showed that elementary school students are more vulnerable to traumatic and stressful events, and are prone to developing mental health problems when facing such event due to the immaturity of their body or cognition ${ }^{[8]}$. In the context of pandemic, because of lack of knowledge and skill about diseases prevention and control, it is very necessary to investigate the status of mental health and its influencing factors during the early COVID-19 pandemic outbreak among elementary school students. Moreover, paying attention to detect early-onset psychological symptoms among elementary school students have broad benefits, especially for school health services and mental health policymaking ${ }^{[3]}$. According to available literature, most of the research related to this pandemic focused on the epidemiology, clinical characteristics of infected patients, the genomic characterization of the virus, and psychological research of medical staff or patients or public population aged more than 14 years [6,9-11], few studies on psychological symptoms status and influencing factors among elementary school students. Present study was aimed to conduct a survey to investigate the psychological symptoms status and its influencing factors among elementary school students during early pandemic.

\section{Methods}

\section{Participants}

The present study was conducted under the approval of the moral and ethical committee of the School of Psychology, Jiangxi Normal University.

With written informed consent from their parents or guardians, elementary school students in grade three to grade six from four Chinese elementary schools took part in our survey in March 17-20, 2020 (approximately after three weeks of online learning courses). Preliminary research showed that students in grade three from these schools had adequate reading levels and could complete the survey independently. With the help of the head teachers, participants received an email and were asked to complete a self-reported survey independently and to return it by the deadline. The survey included indicators of anxiety, depression, COVID-19-related stressors, coping, online learning satisfaction and demographic variables. The response rate was $93 \%$. Questionnaires with more than $15 \%$ of the items unanswered were excluded from the later analysis. A total of 823 elementary school students completed the survey and was used in following analysis. The present study was conducted under the approval of the moral and ethical committee of the School of Psychology, Jiangxi Normal University.

\section{Measurement}

Psychological symptoms. Two indicators (including anxiety, and depression) were used to assess students' psychological symptoms during the pandemic. The GAT-7 ${ }^{[12]}$ and PHQ-9 ${ }^{[13]}$ were used to measure symptoms of anxiety and depression in present study, respectively. The participants were asked to rate perceived anxiety or depression symptoms during the past two weeks from 0 (not at all) to 3 (nearly every day). Scores of 5,10 , and 15 represent the threshold for mild, moderate, (moderately) severe depression or anxiety symptoms.

Participants who had scores of 10 and above, and below 10 were characterized as having M/S and haven't M/S 
anxiety or depression respectively. The Cronbach's a of the GAD-7 and PHQ-9 was .87 and .86 in present study, respectively.

COVID-19-related stressors. The COVID-19-related stressors scale ${ }^{[14]}$ was used to assess the stressors related to infectious disease. The scale includes 16 items, and one of items is listed as "One of your close friends was diagnosed with COVID-19". Participants were asked to response whether they had experienced the event related to COVID-19. A score of 1 indicates that the participants has experienced the stressor related to COVID-19 during the pandemic, while a score of 0 indicates that they has not. The total score of all items was computed. A total score of $0,1-2,3$ and above were characterized as that participants who had experienced none, low, or large number of COVID-19-related stressors.

Participants responded to each item on a four-point scale (1 = I have never used it, 4 = I always used it).

Coping strategy. The brief coping strategy scale ${ }^{[15]}$ was used to measure the frequency of participants' use of coping during the COVID-19 pandemic. The scale includes questions to assess both problem-based coping (e.g., active coping) and emotion-based coping (e.g., denying). Participants responded to each item on a fourpoint scale (1 = I have never used it, 4 = I always used it). In present study, the Cronbach's a values of problembased coping and emotion-based coping were .86 and .79 respectively. The score below (or above) the mean score were characterized as low (or high) level of problem-based coping and emotion-based coping.

Online learning satisfaction. Online learning satisfaction was measured by one item, "Assess perceived satisfaction with individual online courses during the pandemic outbreak", which was rated between 1 (very dissatisfied) and 5 (very satisfied). A total score of below (or above) 3 points were characterized as that participants who had low (or high) level of satisfaction with online course. The students who had 3 points were equally distributed to groups with low or high level of online learning satisfaction

Social demographic characteristics. Social demographic characteristics include gender (male, female), grade, and family social status. Family social status was measured by the sum of the participants' parents' education level ranged from 1 (primary school or below) to five (bachelor's or above), and their family income ranged from 1 (less than 20,000 RMB) to 6 (more than 200,000 RMB). The score below (or above) the mean score were characterized as low (or high) family social status.

\section{Data analysis}

Data analysis was performed using SPSS statistical software version 16.0. First, frequency and percentage were calculated for all variables of interest. Second, the nonparametric Mann-Whitney U test and Kruskal-Wallis test were applied to compare the psychological symptoms by groups. Third, a multivariate logistic regression analysis was performed to identify influenced factors with individual psychological symptoms. The reported Cls were calculated at the $95 \%$ level and statistical significance was set at the $5 \%$ level.

\section{Results}

\section{General characteristics of participants}

The demographic and characteristics of the study population are shown in Table 1. Among the samples of 823 responding participants, the ratio of female to male students was $49.7 \%$ to $50.3 \%$. Regarding their grade, there 
were $345(41.9 \%)$ middle-grade students (including the third or fourth grade, $M_{a g e}=10.7, S D=.77$ ) and 478 $(58.1 \%)$ high-grade students (including the fifth or sixth grade, $\mathrm{M}_{\mathrm{age}}=12.7, \mathrm{SD}=.85$ ).

\section{Status of psychological symptoms by subgroup}

Of the 823 elementary school students, the proportion of students with mild, and M/S depression was $16.4 \%$, and $9.8 \%$ respectively; the proportion of students with mild, and M/S anxiety was $19.4 \%$, and $9.1 \%$ respectively. Students with more than 3 COVID-19-related stressors, high score of emotion-based coping, low score of problem-based coping or online learning satisfaction experienced more M/S symptoms of depression or anxiety. For family social status, individual with low level of family social status were more likely to suffer depression and anxiety symptoms than those with high level of family social status (See table 1).

\section{Insert table 1 here}

\section{Factors influenced with psychological symptoms}

Table 2 showed that large number of COVID-19-related stressors (for depression: OR=1.81, $P<0.05$; for anxiety: $\mathrm{OR}=2.38, \mathrm{P}<0.001$ ), high score of emotion-based coping (for depression: $\mathrm{OR}=3.24, \mathrm{P}<0.001$; for anxiety: $\mathrm{OR}=2.43, \mathrm{P}<0.001$ ) were risk factors for $\mathrm{M} / \mathrm{S}$ psychological symptoms, while high score of problem-based coping (for depression: $\mathrm{OR}=0.47, \mathrm{P}<0.01$; for anxiety: $\mathrm{OR}=.59, \mathrm{P}=0.053$ ), high score of online learning satisfaction (for depression: $\mathrm{OR}=0.58, \mathrm{P}<0.05$ ) were protective factors for $\mathrm{M} / \mathrm{S}$ psychological symptoms. Moreover, high family social status was protective factor for $\mathrm{M} / \mathrm{S}$ depression $(\mathrm{OR}=.61, \mathrm{P}=0.05)$.

\section{Discussion}

In present study, the detection rate of depression was $26.2 \%$, the rate for mild and $\mathrm{M} / \mathrm{s}$ depression were $16.4 \%$ and $9.8 \%$ respectively. Similar result was found for anxiety symptoms. That is, the detection rate of anxiety was $28.5 \%$, the rate for mild and $\mathrm{M} / \mathrm{s}$ anxiety were $19.4 \%$ and $9.1 \%$ respectively. The detection rate of depression was much higher than the study result among elementary student population conducted in Shenzhen City, China (depression rate was $14.1 \%{ }^{[16]}$, and the result related to elementary school students conducted in Wuhan city, China (depression rate was $6.4 \%{ }^{[17]}$. Facing the severe pandemic, elementary school students lack of the related knowledge and skill on prevention and control. In addition, the data was collected at the peak of the pandemic at that period in China, the increasing number of confirmed and suspected cases, lack of effective treatment, and the restriction of outdoor activity also may be the leading reasons for the high detection rate of depression or anxiety symptoms. However, our result was lower than the study among Chinese adolescent population (for depression rate: 44\%; for anxiety rate: $37 \%$ ), which was conducted among adolescents aged 14-18 years rather than elementary school students ${ }^{[6]}$.

Our study showed that high number of COVID-19-related stressors was a risk factor for elementary school student' symptoms of depression and anxiety, which was consistent with previous findings among general public population during other infectious diseases (e.g., SARS) ${ }^{[5]}$. That is, large number of COVID-19-related stressors indicates that the important person of students (e.g., family members or friends) or students themselves were under the high risk of infection, or their daily life was changed completely due to the pandemic 
(e.g., cancelled the vocation trip). Those issues above are harmful to elementary school students physical or mental health.

Consistent with previous studies among public population during SARS ${ }^{[5]}$, our findings showed that problembased coping was a protector in predicting students' psychological symptom, while emotion-based coping was a risk factor. The possible reason might be that problem-based coping might reduce individuals' psychological symptoms by altering the unfavourable environment to support their physical or mental health (e.g., wearing mask when taking outdoor activities). However, individuals who use emotion-based coping (e.g., denial) frequently tend to ignore or avoid stressful events and leave the problematic situation unchanged or allow it to worsen. When individuals engage in emotional-based coping, stress is only temporarily ameliorated, and psychological problems often emerge or become more complex over time.

The result also showed that high level of online learning satisfaction could reduce the symptoms of anxiety. The possible reason might be that, on one hand, elementary school students who have high online learning satisfaction tend to have high self-esteem, and are more likely to use active coping or have high efficacy in coping with stressors ${ }^{[18]}$, which could also promote individual mental health; on the other hand, students could receive social support (a protective e factor of individual psychological symptoms) from their teachers or classmates in online course during pandemic.

For demographic variables, no gender differences were found in the variables of students' psychological symptoms, which was consistent with previous study [19]. It is possible that, when facing stressful event, girls and boys may be equally likely to develop symptoms of depression or anxiety because of their immaturity of their body or brain. With regard to the variables of family social status, the findings of this research are consistent with previous studies ${ }^{[20-21]}$ and indicate that impoverished children are at risk of developing depressive symptoms or poor health. This phenomenon could be explained by evolutionary theory. That is, low social status might be regarded as a potential threat to survival because it could mean less access to resources and less opportunity to cooperate with others. In the modern world, however, low social status may be more connected to symbolic threats to the self and thus may provide a major source of chronic stress and increase the likelihood of obesity, which may presumably alter neuroendocrine functions associated with, for example, depression and untimely death.

Despite the importance of the findings, this study has several limitations. First, the cross-sectional design does not allow for the investigation of changes in individuals' psychological symptoms across different periods of the COVID-19 pandemic and cannot provide a fuller picture of the psychological impact of the outbreak. Second, because all the constructs were assessed by self-report, the estimated relationships among stressors, coping, and psychological symptoms might be biased by the reporter effect. Future research should consider a longitudinal design or use multiple methods to examine the role of stressors, online learning satisfaction and coping in individuals' psychological symptoms during the COVID-19 pandemic. Third, there has been some speculation that Asian cultures tend to use avoidance strategies of emotion-based coping more frequently than Western cultures. Future studies should consider cultural factors when discussing the relationships among the variables in the present study.

\section{Conclusions}


In this study, the status of psychological symptoms among elementary school students were much higher than excepted. The influencing factors of psychological symptoms are multifaceted, including factors of social demographic, number of COVID-19-related stressors, coping strategy, online learning experience. Parents or related person could offer some suggestions for elementary school students to take some suitable coping strategies during the pandemic. Teacher could promote elementary school students' mental health by improving the quality of online course. In addition, school manager should pay more attention to those students who experienced high number of COVID-19-related stressors or those students with low family social status.

\section{Declarations}

\section{Ethics approval and consent to participate}

This study was carried out in accordance with the recommendations of the Research Ethics Committees of the School of Psychology, Jiangxi Normal University, with written informed consent from the participants' parents or guardians.

\section{Consent for publication}

Not applicable.

\section{Availability of data and materials}

The datasets generated and analyzed in this study are not publicly available because of individual privacy considerations and limitations from ethics approval. Information about data is available from the corresponding author on reasonable request.

\section{Competing interests}

The authors declare that they have no competing interests.

\section{Funding}

This study was supported by the Educational Science Foundation of Jiangxi Province, CN (Grant No. 20ZD018; Grant No.16YB033)

\section{Authors' contributions}

The authors alone are responsible for the writing and content of this article. The data were collected by Taohua Huang, and Lingling Huang. Xiaoshan Li drafted the manuscript, while Pengyong Sun, Mingjie Zhou, Li Li, Youtian Shen critically reviewed and revised it. All authors read and approved the final manuscript.

\section{Acknowledgements}

The authors thank all head teachers for collecting research data. We would also like to thank our colleague Professor Fu for advice on the analytic process.

\section{Tables}

Table1 Demographic characteristics of the elementary school students by psychological symptoms Note: ${ }^{\mathrm{a}}$ Mann-Whitney U test; ${ }^{\mathrm{b}}$ Kruskal-Wallis test. 


\begin{tabular}{|c|c|c|c|c|c|c|c|}
\hline \multirow[b]{2}{*}{ characteristic } & \multirow[b]{2}{*}{ Total(\%) } & \multicolumn{3}{|c|}{ depression } & \multicolumn{2}{|c|}{ anxiety } & \multirow[b]{2}{*}{$\mathrm{p}$} \\
\hline & & Mild(\%) & $M / S(\%)$ & $\mathrm{p}$ & Mild(\%) & $M / S(\%)$ & \\
\hline Observations & $823(100)$ & $135 \square 16.4 \square$ & 81ロ9.8ロ & & $160 \square 19.4 \square$ & 75ロ9.1ロ & \\
\hline Gender & & & & $.52^{\mathrm{a}}$ & & & $.22^{\mathrm{a}}$ \\
\hline Female & 409ロ49.7ロ & $59(14.4)$ & $43(10.5)$ & & $71(17.4)$ & $37(9.0)$ & \\
\hline Male & $414 \square 50.3 \square$ & $76(18.4)$ & $38(9.1)$ & & $89(21.5)$ & $38(9.1)$ & \\
\hline Grade & & & & $.84^{\mathrm{a}}$ & & & $.55^{\mathrm{a}}$ \\
\hline Middle & $345 \square 41.9 \square$ & $59(17.1)$ & $31(9.0)$ & & 66 & $29(8.4)$ & \\
\hline grade & & & & & (19.1) & & \\
\hline High grade & $478 \square 58.1 \square$ & $76(15.8)$ & $50(10.5)$ & & $94(19.7)$ & $46(9.6)$ & \\
\hline $\begin{array}{l}\text { Family social } \\
\text { status }\end{array}$ & & & & $\mathrm{P}<.05^{\mathrm{a}}$ & & & $\mathrm{P}<.05^{\mathrm{a}}$ \\
\hline Low & $411 \square 49.9 \square$ & $70 \square 17.1 \square$ & $52 \square 12.7 \square$ & & $91 \llbracket 22.1 \square$ & $41 \square 10.0 \square$ & \\
\hline High & $412 \square 50.1 \square$ & $65 \square 15.8 \square$ & $29 \square 7.1 \square$ & & 69ロ16.7ロ & $34 \square 8.3 \square$ & \\
\hline $\begin{array}{l}\text { Number of } \\
\text { stressors }\end{array}$ & & & & $\mathrm{P}<.001^{\mathrm{b}}$ & & & $\mathrm{P}<.001 \mathrm{~b}$ \\
\hline None & $132 \square 16.0 \square$ & $10 \square 7.6 \square$ & $8 \square 6.1 \square$ & & $12 \square 9.1 \square$ & $6 \square 4.5 \square$ & \\
\hline $1-2$ & $405 \square 49.2 \square$ & $69 \square 17.0 \square$ & $33 \llbracket 8.2 \square$ & & $82 \square 20.2 \square$ & $27 \square 6.7 \square$ & \\
\hline More than & $286 \square 34.8 \square$ & $56 \square 19.6 \square$ & $40 \square 14.0 \square$ & & $66 \square 23.1 \square$ & $42 \square 14.7 \square$ & \\
\hline 3 & & & & & & & \\
\hline Problem- & & & & $\mathrm{P}<.001{ }^{\mathrm{a}}$ & & & $\mathrm{P}<.05^{\mathrm{a} * *}$ \\
\hline based coping & & & & & & & \\
\hline Low & $411 \square 49.9 \square$ & 81ロ19.7ロ & $51 \square 12.4 \square$ & & 89ロ21.7凹 & $43 \llbracket 10.5 \square$ & \\
\hline High & $412 \square 50.1 \square$ & $54 \llbracket 13.1 \square$ & $30 \square 7.3 \square$ & & $71 \square 17.2 \square$ & $32 \square 7.8 \square$ & \\
\hline Emotion- & & & & $\mathrm{P}<.001^{\mathrm{a}}$ & & & $\mathrm{P}<.001^{\mathrm{a}}$ \\
\hline based coping & & & & & & & \\
\hline Low & $411 \square 49.9 \square$ & $49 \square 11.9 \square$ & $28 \square 6.8 \square$ & & $59 \square 21.7 \square$ & $27 \square 10.5 \square$ & \\
\hline High & $412 \square 50.1 \square$ & $86 \square 20.8 \square$ & $53 \square 12.9 \square$ & & $101 \square 17.2 \square$ & $48 \square 7.8 \square$ & \\
\hline Online & & & & $\mathrm{P}<.001^{\mathrm{a}}$ & & & $\mathrm{P}<.001^{\mathrm{a}}$ \\
\hline learning & & & & & & & \\
\hline
\end{tabular}


satisfaction

Low $\quad 411 \square 49.9 \square \quad 81 \square 19.7 \square \quad 52 \square 12.7 \square \quad 101 \square 24.5 \square \quad 40 \square 9.7 \square$

High $\quad 412 \square 50.1 \square \quad 54 \square 13.1 \square \quad 29 \square 7.0 \square \quad 59 \square 14.3 \square \quad 35 \square 8.5 \square$

Table2 Multivariate logistic regression analysis of factors influenced with M/S psychological symptoms

\section{References}

1. Guan WJ, Ni ZY, Hu Y, et al. Clinical characteristics of coronavirus disease 2019 in china. New Engl J Med. 2020. Doi:10.1056/NEJMoa2002032.

2. World Health Organization. Coronavirus disease (COVID-19) Pandemic. 2020. https://www.who.int/emergencies/diseases/novel-coronavirus-2019.

3. National Helath Commision of the People's Republic of China. Coronavirus disease (COVID-19) Pandemic update.. 2020. Http://www.nhc.gov.cn/yjb/s7860/- 202003/8331f126d3854413b6ea323009fbbcc5.shtml.

4. Pfefferbaum B, North CS. Mental health and the covid-19 pandemic. New Engl J Med. 2020. doi: 10.1056/NEJMp2008017.

5. Main A, Zhou Q, Ma Y, Luecken LJ, Liu X. Relations of sars-related stressors and coping to chinese college students $\backslash$ " psychological adjustment during the 2003 beijing sars pandemic. J Couns Psychol. 2011;58(3):410-23.

6. Qi M, Zhou S, Guo Z, et al. The effect of social support on mental health in Chinese adolescents during the outbreak of COVID-19. J Adolescent Health. 2020;67(4):514-8.

7. Geary DC. Reflections of evolution and culture in children's cognition. implications for mathematical development and instruction. Am Psychol. 1995;50(1):24-37.

8. Raskauskas J. Multiple peer victimization among elementary school students: relations with socialemotional problems. Soc Psychol Educ. 2010;13(4):523-39.

9. Li Z, Ge J, Yang M, et al. Vicarious traumatization in the general public, members, and non-members of medical teams aiding in covid-19 control. Brain Behav Immun. 2020.

doi:https://doi.org/10.1016/j.bbi.2020.03.007.

10. Huang C, Wang Y, Li X, et al. Clinical features of patients infected 265 with 2019 novel coronavirus in Wuhan, China. Lancet. 2020;395:497-506.

11. Chen N, Zhou M, Dong X, et al. Epidemiological and clinical 268 characteristics of 99 cases of 2019 novel coronavirus pneumonia in Wuhan, China: a descriptive 269 study. Lancet. 2020;395:507-13.

12. He XY, Li CB, Qian J, Cui HS, Wu WY. Reliability and validity of a generalized anxiety scale in general hospital outpatients. Shanghai Arch Psych. 2010;22(4):200-3.

13. Xiong N, Fritzsche K, Wei J, Hong X, Leonhart R, Zhao X. Validation of patient health questionnaire (phq) for major depression in chinese outpatients with multiple somatic symptoms: a multicenter cross-sectional study. J Affect Disorders. 2015;174:636-43. 


\begin{tabular}{|c|c|c|c|c|c|c|}
\hline \multirow{2}{*}{ characteristic } & \multicolumn{3}{|c|}{ Depression } & \multicolumn{3}{|c|}{ anxiety } \\
\hline & OR & $95 \% \mathrm{CI}$ & $P$-value & OR & $95 \% \mathrm{CI}$ & $P$-value \\
\hline \multicolumn{7}{|l|}{ Gender (ref: Female) } \\
\hline Male & .87 & $(.54,1.39)$ & .554 & 1.02 & $\begin{array}{l}(.63, \\
1.66)\end{array}$ & .939 \\
\hline \multicolumn{7}{|l|}{ Grade (ref: High) } \\
\hline Middle & 1.21 & $(.74,1.99)$ & .347 & 1.20 & $\begin{array}{l}(.73 \\
1.99)\end{array}$ & .473 \\
\hline \multicolumn{7}{|l|}{ Family social status (ref: Low) } \\
\hline High & .61 & $(.36 \square 1.00)$ & .05 & .86 & $\begin{array}{l}(.52 \\
1.44)\end{array}$ & .577 \\
\hline $\begin{array}{l}\text { Number of stressors (ref: Non } \\
\text { stressor) }\end{array}$ & & & & & & \\
\hline 1-2 stressors & 2.59 & $(1.16,581)$ & $\mathrm{P}<.05$ & 3.68 & $\begin{array}{l}(1.52 \\
8.98)\end{array}$ & $\mathrm{P}<.01$ \\
\hline More than 3 stressors & 1.81 & $(1.09,2.99)$ & $\mathrm{P}<.05$ & 2.38 & $\begin{array}{l}(1.42, \\
3.98)\end{array}$ & $\mathrm{P}<.001$ \\
\hline \multicolumn{7}{|l|}{ Problem-based coping (ref: Low) } \\
\hline High & .47 & $(.28, .81)$ & $\mathrm{P}<.01$ & .59 & $\begin{array}{l}(.34 \\
1.00)\end{array}$ & .053 \\
\hline \multicolumn{7}{|l|}{ Emotion-based coping (ref: Low) } \\
\hline High & 3.24 & $\begin{array}{l}(1.91 \\
5.51)\end{array}$ & $\mathrm{P}<.001$ & 2.43 & $\begin{array}{l}(1.41 \\
4.16)\end{array}$ & $\mathrm{P}<.001$ \\
\hline \multicolumn{7}{|l|}{ Online learning satisfaction (ref: } \\
\hline High & .58 & $(.34, .98)$ & $\mathrm{P}<.05$ & .87 & $\begin{array}{l}(.51, \\
1.48)\end{array}$ & .601 \\
\hline
\end{tabular}

14. Li X, Wu H, Meng F, Li L, Wang Y, Zhou M. Relations of covid-19-related stressors and social support with chinese college students' psychological response during the covid-19 pandemic. Front Psychiatry. 2020;11:551315. Doi:10.3389/fpsyt.2020.551315. 
15. Xie Y. The research on the reliability and validity of the brief coping strategy questionnaires. Chin J Clin Psychol. 1998;6(2):114-5.

16. Yang J, Chen K, Chen Y, Huang C, et al. Depressive Symptoms and the Influencing Factors Among Primary students. Med Information. 2014; (10): 183-184.

17. Gong Y, Ding J, Zhang M, Kang C, Wang K, et al. Relationships among personality traits, resilience, and depressive symptoms of students in Wuhan City. J Hygiene Research. 2020;49(2):173-8.

18. Sideridis GD. Goal orientation, academic achievement, and depression: evidence in favor of a revised goal theory framework. J Educ Psychol. 2005;97(3):366-75.

19. Demir T, Karacetin G, Demir DE, Uysal O. Epidemiology of depression in an urban population of turkish children and adolescents. J Affect Disorders. 2011;134(1):68-176.

20. Dallaire DH, Cole DA, Smith TM, Ciesla JA, Lagrange B, Jacquez FM. Predicting children's depressive symptoms from community and individual risk factors. J Youth Adolescence. 2008;37(7):830-46.

21. Åslund C, Leppert J, Starrin B, Nilsson KW. Subjective Social Status and Shaming Experiences in Relation to Adolescent Depression. Arch Pediat Adol Med. 2009;163(1):55-60. 